\begin{tabular}{|c|c|c|c|c|c|}
\hline $\begin{array}{l}\text { Year. } \\
\text { II } 38\end{array}$ & & Moon. & & Remarks. & \\
\hline 1139 & $\ldots$ & 2,10 & & & \\
\hline I 145 & $\ldots$ & 6 & $\ldots$ & Black shadows and spots. & \\
\hline 1160 & $\ldots$ & 8 & & & \\
\hline 1185 & $\ldots$ & I & $\cdots$ & Size of an egg. & \\
\hline I 186 & $\cdots$ & 5 & $\cdots$ & ", & \\
\hline 193 & $\cdots$ & $\int_{12}^{\text {II }}$ & & & \\
\hline $\begin{array}{l}1200 \\
1202\end{array}$ & $\cdots$ & $8, \mathbf{I} 2$ & & & \\
\hline $\begin{array}{l}1202 \\
1204\end{array}$ & $\cdots$ & 12 & $\cdots$ & Size of an egg. & \\
\hline 1205 & $\ldots$ & 4 & & & \\
\hline 1238 & $\ldots$ & IO & & & \\
\hline 1276 & $\ldots$ & - & $\cdots$ & Size of a goose's egg. & \\
\hline $\mathbf{I} 370$ & $\cdots$ & - & $\cdots$ & $\begin{array}{l}\text { Spots were frequently } \\
\text { during this year. }\end{array}$ & observed \\
\hline 2511 & $\ldots$ & 5 & $\ldots$ & Black shadows. & \\
\hline 1529 & $\cdots$ & 2 & $\cdots$ & , & \\
\hline 1617 & ... & - & & ALEXANDER & Hosie \\
\hline
\end{tabular}

NATIONAL WATER-SUPPLY EXHIBITION

H YDE PARK and Trafalgar Square experiences have very plainly shown that the simplest way to induce a clamorous populace to forget what they fancy they want, is to let them hold their meetings and pass resolutions. It is a matter of such very small exertion to hold up a hand in favour of a resolution compared with taking any personal trouble to see that any steps are taken towards carrying it into effect. Human nature is only in certain phases influenced by a man's occupation, and whether resolutions are passed by "labourers" or by "professional gentlemen," they stand much the same chance of being forgotten after the press has recorded that they have been passed. Last year the Society of Arts in loyal response to the request of its Royal President, held a conference to discuss the watersupply question. After two days' work a resolution was carried urging that a small scientific commission should be appointed to collect information and suggest further inquiries on the subject. Twelve months elapsed and a few days ago another conference was held, when it was made known that the only step taken with regard to that resolution was that just before the Conference it had reached the Lords of the Treasury. Last year the Society directed that a résumé and sort of index should be made of what had been done by Parliamentary inquiries and official reports with regard to water-supplies, and the result was a volume called "Notes on Previous Inquiries," which, though very incomplete, may serve as a basis for a larger and more comprehensive work. The very fact of the imperfections in these notes showed to those more immediately connected with their compilation the need of enlisting wider sympathies if anything of real value was to be printed. A letter in the Times of April I4 of this year mentioned that although the notes had been published for many months, "not a single word" had been sent in response to the request printed on the back of the titlepage that suggestions or corrections should be sent to the secretary. The idea was then suggested of founding a permanent free museum for the purpose of keeping before the public mind those subjects, apart from the question of low rates only, which should be considered in arranging water-supplies. It was decided that a temporary exhibition should be first tried as an experiment and after some difficulties in finding it a locale, the management of the Royal Aquarium kindly arranged for the use of the south gallery for the purpose. This exhibition is now open and a handbook is issued. It is marked "under revision," and on the title-page attention is appropriately drawn to the fact that it is the first public exhibition of the kind.

This handbook, we are told, has been drawn up under great disadvantages in many ways. One great difficulty has been that the exhibition has grown beyond what seemed at first likely to be its extent, and entries for the handbook have come from time to time, though but slowly. This was, perhaps, to be expected in an exhibition, the first of its kind, which was, therefore, to some extent, an experiment; and that many should hold aloof till success was assured was but natural. Although this gradual growth is a matter that must be a satisfaction to those interested in spreading a knowledge of what a study of water-supply means, it has entailed much unexpected labour on the part of the management.

Among those who have helped in the scientific sections are-Col. Beaumont, M.P., Col. Bolton, Baldwin Latham, F.R.S., J. G. Symons, F.R.S., J. E. Gardner, F.S.A., Dr. Granville Cole, Prof. Wanklyn, Prof. G. Bischoff, W. Cooper, Joseph Lucas, F.G.S., A. T. Atchison, M.A., C. E. De Rance, H.M.G.S., F.G.S., J. B. Jordan, F.G.S.

The comprehensive scope of the exhibition may be gathered from the following list of the sections into which it is divided :-

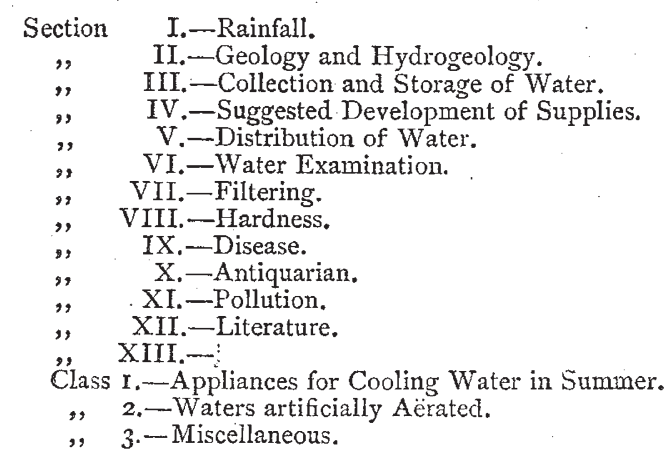

A scientific committee has been formed to draw up a report on the exhibition, especially to point out what defects should be remedied in future exhibitions of the kind, and it is announced that next week "demonstrations" will be given on the sections embracing scientific apparatus.

\section{NATURAL SCIENCE DEGREES AT OXFORD}

MANY of our readers have no doubt noticed the scheme which some soi-disant "friends of science" in authority at Oxford have brought forward professedly in the interests of science. One of the prime movers in the new scheme for the creation of B.N.S. and M.N.S. degrees is Canon Liddon, who insists that for the degree of Arts Greek shall be indispensable, but for the inferior degrees in science may be dispensed with. Since the meeting of congregation at which the scheme was discussed, there has been much correspondence in the Times on the subject, the letters of most importance being those of Canon Liddon and Prof. Odling. The former in his correspondence professes to have the interests of natural science purely at heart in the creation of the new degree, which, he maintains, would give facilities to a much wider class to obtain the stamp of the University than if Greek were insisted on, as he maintains must be the case with the degree of the university. The opposition of Prof. Odling and those who think with him, is not to the creation of a degree in natural science, but to any course that would degrade it in public estimation. He urges on the university the desirability of framing such statutes in reference to any such degree, as shall assure it a high place in general estimation, and shall more especially obtain for it the approval and sympathy of the cultivators of natural science. He considers it important to this end that the possession of a degree in natural science shall imply on the part of the student, first, general cultivation, and second, special knowledge in some branch of science. But according to the proposed innovation, if 
such general cultivation is based on classical studies, the student cannot get the new degree, but must take the Arts degree, which quoad natural science must be held to be an inferior degree. But he shows that by the proposed statute the science graduate need know little of natural science, as be may take his degree in the School of Mathematics; thus he shows a degree in natural science might be confined to those who had never got beyond its rudiments; why, then, he asks, does not Canon Liddon propose a new degree in mathematics, and thus "assign one set of students a new decoration which will honourably represent their real attainments." Prof. Odling shows that many of those who in the debate insisted on Greek being necessary to a degree in Arts, admitted it was not necessary to a liberal education; and thus, a degree in Arts must be held as something different from a certificate of liberal education.

"If, then, it be once conceded, and the concession was made without hesitation, that Greek is not essential to a liberal education, and that the studies of mathematics and natural science and modern languages do constitute liberal studies, how is it possible," Prof. Odling asks, "to refuse a degree in Arts to those who, in addition to considerable acquaintance with Latin and German, are possessed of special attainments in either mathematics or natural science, and also of not inconsiderable attainments in the alternative one of these two subjects."

According to the proposed statutes, Prof. Odling concludes, the new natural science degree, while it will certify to an ignorance of Greek, will not certify to a knowledge of natural science.

In reply to Prof. Odling, Canon Liddon asserts that Greek "is an instrument of unrivalled delicacy for effecting the general training of the mental powers, and especially for imparting to them those habits of exactness and refinement without which it is impossible to reach the higher characteristics of an educated man." "An education which excludes Greek," he maintains, "is certainly less liberal than an education which insists on it." For the liberal education of the highest order, only, according to Canon Liddon, to be attained by learning Greek, the highest honour of the University should be reserved ; to a lower degree of liberality attained through means of natural science, even with a training in Latin or German, an inferior honour can only be conceded.

At present we give these arguments and assertions without comment.

\section{NOTES}

AN influential committee has been recently formed for the purpose of obtaining subscriptions to procure a portrait of Dr. W. B. Carpenter, F.R.S., to be presented to the University of London as a permanent memorial of his long and assiduous labours on behalf of that institution. We need not say one word to commend the object of the "Carpanter Memorial Committee" to the practical consideration of our readers; Dr. Carpenter's services to science and to the London University are so well known, that we are confident the proposal of the Committee will meet with a satisfactory response. Earl Granville is chairman of the Committee, which contains many names eminent in science, as well as in other departments. The honorary treasurers are Sir John Lubbock and Dr. William Smith, to either of whom cheques and post-office orders should be made payable. Subscriptions should be sent to either of the honorary secretaries, J. G. Fitch, 5, Lancaster Terrace, Regent's Park, or G. Knight Watson, Society of Antiquaries, Burlington House.

WE take the following from the Gardeners' Chronicle:- "The London Gazotte of the 24th inst. announces that Her Majesty has been graciously pleased to confer the appointment of Com. panion of the Most Distinguished Order of St. Michael and St. George on George Bentham, Esq. While we rejoice to find some official recognition made of the life-long services to botany rendered by $\mathrm{Mr}$. Bentham, we regret that such recognition has been so tardy, and that it is so inadequate. Such distinctions are not as a rule highly prized by scientific men, inasmuch as they are not specially appropriate to them; but if paid at all, they should be prompt and adequate." Baron von Müller, Government Botanist of Victoria, has been promoted to the dignity of Knight Commander of the same order, and a welldeserved knighthood has been bestowed on Mr. Henry Bessemer.

WE regret to record the death at Halifax, Nova Scotia, of Prof. John James Mackenzie, at the age of thirty-two. After graduating from Dalhousie University, and passing several years as a teacher of mathematics and physics, he went in 1873 to Germany, where he underwent a thorough course of physical training at Leipzig. Here he received, in 1876 , the doctor's degree, presenting an able dissertation on the absorption of gases by saline solutions, based on a most exhaustive and exten. sive series of experiments. The following year was passed in research in Helmholtz's laboratory at Berlin, where Dr. Mackenzie, among other results, succeeded in showing that in the relations hitherto supposed to exist between light and electricity, the optical phenomena observed were not due to electric tension itself, but probably in a secondary manner to the heat evolved. In 1877 he accepted a call to the Chair of Physics at Dalhousie University, Nova Scotia. At the commencement of a scientific career from which much was expected by his numerous friends, he was suddenly taken away by an insidious complaint induced a year since by the inhalation of the nitrous fumes from a Bunsen battery.

M. GyLden has been elected a Corresponding Member in the Astronomical Section of the Paris Academy in place of the late Father Secchi.

WE notice the appearance in May of the German Fahres. berichte ïber die Fortschritte der. Chemie for 1877 . The present volume forms the thirtieth of the series founded by Liebig and Kopp, and is at present under the editorial supervision of Prof. Fittica of Marburg, assisted by a corps of eleven German and Austrian chemists. It is by far the most important and the most extensive of all annual reviews, and affords to even a superficial observer an interesting glimpse into the variety and extent of the chemical discovery of our day. Of its 1,400 pages, 196 are devoted to theoretical and physical chemistry, I 20 to inorganic chemistry, 7I4 to organic chemistry, 66 to analytical chemistry, ${ }^{5} 2$ to technical chemistry, $\mathrm{rO}_{4}$ to mineralogy, and 46 to "chemical geology. Of the space devoted to organic chemistry-more than one-half of the work-364 pages are occupied with the chemistry of the aromatic series, 48 with animal chemistry, 47 with vegetable chemistry, \&c. The index of authors contains over 1,750 names, and in comparison with the indices for 1867 ( 850 authurs) and 1857 ( 720 authors) shows the rapid increase of late years in the number of those devoted. to chemical research. Nine volumes of the fahresbericht are now out of print, and complete sets are quoted at 800 marks. Individnal volumes bring as high as 100 marks. German booksellers state that this rarity is occasioned in a notable."degree by recent extensive purchases for public and private libraries in the United States.

DURING the past week Etna has been in active and increasing eruption, A very consicerable number of new craters have opened, and that on both flanks of the mountain. The lava has reached many miles from the mountain, almost to the River Alcantara, laying waste the surrounding country. The village of Mojo has been destroyed, and others are threatened. 